\title{
EDUCAÇÃO PARA A DIVERSIDADE: UM ESTUDO DE CASO NA MODALIDADE EAD
}

\author{
DUQUE DE CAXIAS/RJ JULHO/2018
}

\author{
Rosane Cristina de Oliveira - UNIGRANRIO - rosanecrj@hotmail.com \\ Andressa Maria Freire da Rocha Arana - UNIGRANRIO - andressa.rocha@unigranrio.edu.br \\ Lúcia Inês Kronemberger de Andrade - UNIGRANRIO - lines@unigranrio.edu.br \\ Herbert Gomes Martins - UNIGRANRIO - hmartins@unigranrio.edu.br
}

Tipo: Relato de Experiência Inovadora (EI)

Categoria: Conteúdos e Habilidades

Setor Educacional: EDUCAÇÃO SUPERIOR

\begin{abstract}
RESUMO
Este estudo tem como objetivo apresentar uma reflexão em relação ao aspecto inovador das disciplinas institucionais na modalidade EaD, chamando a atenção para a dimensão da formação humana. Neste estudo, enfatizamos o processo de elaboração e aplicação da disciplina intitulada Sociodiversidade, Responsabilidade e Comprometimento Social, cursada por todos os discentes da Universidade do Grande Rio, no segundo período de seus respectivos cursos. Metodologicamente, é um estudo exploratório e foram realizadas entrevistas com docentes / tutores responsáveis pela disciplina ao longo do primeiro e segundo semestre de 2017, enfatizando suas respectivas experiências com a disciplina.
\end{abstract}

Palavras-chave: Sociodiversidade; EaD; Formação Humana; Disciplina Institucional 


\section{Introdução}

Nas últimas décadas, o ensino passou por algumas transformações especialmente em relação ao desenvolvimento das novas tecnologias e a expansão da modalidade EaD de ensino-aprendizagem. Nesta perspectiva, constantemente, as instituições de ensino superior buscam por metodologias e usos da tecnologia para aprimorar os métodos de ensino. Atrelado a esta busca, as políticas de inclusão digital são fundamentais para que métodos e novas concepções estratégicas de aprendizagem obtenham os resultados esperados, quais sejam: assimilação do conhecimento, reflexão e aplicabilidade.

Este artigo faz parte dos estudos desenvolvidos pelo grupo de pesquisa Docência e Tutoria na Educação à Distância: práticas e desafios, cadastrado no CNPQ. Neste grupo, as pesquisas estão voltadas para as seguintes linhas de pesquisa: a) docência e tutoria na educação superior à distância: melhores práticas; e, b) políticas públicas, inclusão digital e cidadania em educação à distância.

O uso de plataformas digitais voltadas para a educação, em constante aprimoramento, possibilitam a execução de inúmeras atividades que corroboram para a formação humana dos discentes, especificamente em relação ao estudo de conteúdo de disciplinas que são idealizadas para esta finalidade. Neste sentido, este trabalho tem como objetivo analisar a inclusão de uma disciplina na modalidade $\mathrm{EaD}$, a partir da aplicação das metodologias ativas. Trata-se da experiência docente em relação à disciplina intitulada Sociodiversidade, Responsabilidade e Comprometimento Social. De caráter institucional, a referida disciplina é cursada por todos os alunos no segundo período de seus respectivos cursos da Universidade do Grande Rio.

Do ponto de vista metodológico, optou-se por método de pesquisa exploratório em relação ao levantamento de dados/informações sobre a concepção e elaboração da proposta da disciplina, a escolha do conteúdo a ser abordado, a dinâmica e as atividades, bem como a leitura da bibliografia pertinente. A pesquisa exploratória, além de conter o levantamento bibliográfico, também podem conter a obtenção de informações através de entrevistas e / ou análise de exemplos que de certa forma esteja atrelado à problemática em torno do objeto estudado (Gil, 2007). Neste sentido, foram realizadas entrevistas com três docentes (professores tutores) atuantes na disciplina, com o intuito de observar como o conteúdo é abordado e, também, os resultados obtidos através dos trabalhos desenvolvidos pelos alunos.

O artigo está organizado em duas partes. A primeira parte discute, conceitualmente a questão do ensino-aprendizagem, chamando a atenção para a modalidade EaD e, em 
seguida, apresenta a concepção de disciplinas institucionais desenvolvida pela IES. Na segunda parte do artigo apresentamos o estudo de caso em relação à disciplina de Sociodiversidade, Responsabilidade e Comprometimento Social, com o intuito de dialogar sobre a formação humana e a reflexão sobre temáticas como: diversidade, preconceito, relações de gênero, questão étnico-racial, direitos humanos, cidadania, inclusão social do público da educação especial (deficiências, transtornos globais do desenvolvimento, autismo e altas habilidades), sustentabilidade e responsabilidade social.

\section{Disciplinas institucionais: um novo conceito em ensino-aprendizagem na modalidade EaD}

A educação à distância tornou-se, a partir da última década do século XX, um dos processos de ensino-aprendizagem mais importantes, especialmente nas Instituições de Ensino Superior. Este processo diz respeito ao ensino-aprendizagem mediado por tecnologias. É importante destacar que a educação à distância é reconhecida como um fenômeno do ciberespaço e da cibercultura, termos amplamente debatidos por Pierre Levy (1999). Para o autor, o ciberespaço compõe um dos principais processos comunicacionais da atualidade, ou seja,

"[...]o espaço cibernético é um terreno onde está funcionando a humanidade, hoje. É um novo espaço de interação humana que já tem uma importância enorme sobretudo no plano econômico e científico e, certamente, essa importância vai ampliar-se e vai estender-se a vários outros campos, como por exemplo na Pedagogia, Estética, Arte e Política. O espaço cibernético é a instauração de uma rede de todas as memórias informatizadas e de todos os computadores". (LÉVY, 1996, p. 35)

Neste sentido, o ciberespaço é um elemento da sociedade em rede e que, constantemente, redefine o fluxo das relações sociais. No que tange o processo educacional, o ciberespaço compõe um dos instrumentos fundamentais de ensinoaprendizagem, tanto do ponto de vista formal (conforme pode-se perceber a importância da educação à distância), como informal.

A cibercultura, conforme salientou Bergmann (2006, p. 24), "é definida como um conjunto de técnicas, práticas, atitudes, modos de pensamento e valores que se desenvolvem juntamente com o crescimento da internet como um meio de comunicação, que surge com a interconexão mundial de computadores." Assim, na condição de espaço de sociabilidade, os elementos culturais são amplamente compartilhados.

Os ambientes virtuais de aprendizagem podem ser definidos como um dos elementos proporcionados pela cibercultura em relação, especificamente, à educação. De acordo 
com Santos (2010, p. 37-38), "a educação online é o conjunto de ações de ensino e aprendizagem ou ator de currículo mediados por interfaces digitais que potencializam práticas comunicacionais interativas e hipertextuais." Assim, a educação à distância, cada vez mais, assume protagonismo no processo de aprendizagem e difusão cultural, tanto nos espaços educacionais formais, como nas demais organizações corporativas.

Neste sentido, salientamos que a concepção e elaboração de disciplinas institucionais, oferecidas na modalidade $\mathrm{EaD}$, compõe uma estratégia importante no que concerne a busca pela difusão cultural dos valores institucionais, bem como garantir aos discentes, dentro do processo ensino-aprendizagem, construir saberes diversificados do ponto de vista da formação humana. Portanto, as disciplinas institucionais são compostas por oito unidades de aprendizagem, de acordo com o Plano de Ensino, cujos objetivos respondem aos requisitos básicos exigidos pelos parâmetros curriculares e pelo Plano de Desenvolvimento Institucional (PDI).

Os pilares estratégicos do Plano de Desenvolvimento Institucional (PDI) da Universidade do Grande Rio (UNIGRANRIO), são a sustentabilidade, o empreendedorismo e empregabilidade, que revelam a determinação em ser uma universidade moderna, ágil e plural, ou seja, ajustada às expectativas da contemporaneidade. Como universidade moderna, procura adotar metodologias coerentes com os princípios filosóficos que a regem, fundamenta-se em ações conjuntas, e a transversalidade faz-se presente na responsabilidadesocial por ela assumida.

O entendimento de Responsabilidade Social (RS) na UNIGRANRIO é baseado no conceito expresso no SINAES (Sistema Nacional de Avaliação da Educação Superior), que preconiza o aprofundamento dos compromissos e responsabilidades sociais das instituições de educação superior.

$\mathrm{Na}$ UNIGRANRIO a responsabilidade social institucional atua nas seguintes linhas de ação:

a. inclusão social;

b. desenvolvimento econômico e social;

c. defesa do meio ambiente, da memória cultural, da produção artística e do patrimônio cultural.

A RS foi assumida na IES como forma de dar continuidade ao compromisso comunitário com abordagem diferente do que vinha sendo feito através da filantropia. Neste sentido, a RS passa a ser um tema que transpassa todas as atividades e diz respeito à uma 
instituição na sua relação com a empresa mantenedora, que deve zelar pelos seus compromissos sociais, fiscais, legais e trabalhistas. Esse é o exercício básico da Responsabilidade Social.

A internalização do tema Responsabilidade Social na gestão da instituição, faz com que a UNIGRANRIO procure atuar de maneira ética com todos os que se relaciona, amparada em valores os quais fundamentam sustentabilidade, a empregabilidade e 0 empreendedorismo, como propósitos conceituados no PDI. Estimula-a para que adote e incentive medidas de proteção aos recursos ambientais e, por meio das atividades que desenvolve, promover a redução das desigualdades sociais.

A responsabilidade social constitui-se tema irradiador voltado para a formação integral, a produção e disseminação de conhecimentos, por meio do ensino, da pesquisa e da extensão.

No ano de 2015 a UNIGRANRIO foi contemplada com o selo Instituição Socialmente Responsável, conferido pela Associação Brasileira de Entidades Mantenedoras do Ensino Superior (ABMES) certificando a participação na 11 a Campanha da Responsabilidade Social do Ensino Superior Particular. Em 2017, manteve a insígnia, que é reconhecida como indicador de compromisso com os valores institucionais construídos ao longo de sua trajetória.

\section{Sociodiversidade, Responsabilidade e Comprometimento Social: formação humana em ambiente virtual de aprendizagem}

De acordo com as Diretrizes Curriculares Nacionais para a Educação das Relações Étnico-Raciais e para o Ensino de História e Cultura Afro-Brasileira e Africana (2004, p. 18-19), um elemento fundamental que deve nortear a consciência política e histórica da diversidade é, entre outras, a "igualdade básica de pessoa humana como sujeito de direitos", e, no que tange o fortalecimento de identidades e de direitos, "a ampliação do acesso a informações sobre a diversidade da nação brasileira e sobre a recriação das identidades, provocada por relações étnico-raciais".

A construção do conteúdo da disciplina de Sociodiversidade, Responsabilidade e Comprometimento Social, na condição de disciplina institucional segue tanto as determinações de conteúdo dos Parâmetros Curriculares Nacional, como as temáticas que são exigidas para compor o aspecto de formação geral. Esta disciplina é comporta por oito unidades aprendizagem, contemplando as seguintes temáticas: 
1) Sociodiversidade e formação da identidade cultural dos povos (discutindo relações étnico-raciais, gênero, sexualidade e cidadania);

2) Direitos humanos, inclusão do público-alvo da educação especial e acessibilidade;

3) Multiculturalismo e globalização (enfatizando a cultura do consumo e a diversidade cultural em decorrência da globalização);

4) Políticas Públicas (chamando a atenção para as políticas nas áreas de habitação, saneamento, transporte, saúde, segurança, defesa, educação e a legislação para pessoas autistas);

5) Democracia e ética (destacando a necessidade de conduta ética para o desempenho profissional e ação empreendedora);

6) Desenvolvimento Sustentável e gestão socioambiental (apresentando uma reflexão sobre sustentabilidade, educação ambiental e ecoeficiência);

7) Relações Comunitárias (enfatizando dimensões fundamentais, tais como: voluntariado, investimento social e a importância das ações não governamentais);

8) Responsabilidade Social (discutindo a questão corporativa e ambiental a partir do ponto de vista do Estado e da responsabilidade das organizações em relação à sociedade e ao meio ambiente).

Do ponto de vista didático, as oito unidades de aprendizagem são disponibilizadas no Ambiente Virtual de Aprendizagem dentro dos seguintes critérios: a) cada unidade possui uma apostila com conteúdo teórico, recursos de aprendizagem (podcast, infográfico, vídeos) e vídeo-aulas gravadas, em geral, pelo professor responsável pela elaboração do conteúdo da disciplina.

A avaliação da disciplina é nota única, ou seja, o discente realiza atividades ao longo do semestre, cumulativas e, ao final obtém uma nota. Estas atividades, podem variar desde a construção de um projeto social, com o intuito de despertar no aluno uma forma de atrelar teoria à prática, até a elaboração de reflexões que auxiliem o discente na construção de uma "cultura da paz".

De acordo com três professores tutores da disciplina, as temáticas abordadas apresentam relevância no processo de reflexão, especialmente, em relação às temáticas 
como preconceito racial, sexualidade e ética. Para os docentes, os debates nos fóruns de discussão e os trabalhos finais apresentados demonstram o amadurecimento dos alunos a partir da percepção de sua própria conduta. Para o entrevistado A, "muitos alunos tinham uma concepção errada do que é preconceito racial, por exemplo. Depois das leituras e debates, muitos disseram que mudaram sua forma pensar em relação ao racismo e questões de gênero. Isso é muito importante!"

O entrevistado B relatou uma experiência nas discussões sobre gênero, "o aluno me procurou para dizer que estava surpreso ao ler sobre as questões de gênero da apostila, e que não sabia o quanto ele mesmo era preconceituoso. O mais interessante foi ouvir dele que iria mudar de conduta?'

Outra questão que foi relatada pelos professores foram as dimensões da violência e a insegurança. Segundo o entrevistado $\mathrm{C}$, muitos alunos, quando realizavam a leitura sobre políticas públicas, direitos humanos e inclusão social, argumentavam que "achavam que direitos humanos defendia bandido, entretanto, depois de refletir e compreender que direitos humanos é proteção à vida, em geral mudaram o discurso"

Um trabalho importante realizado ao longo do primeiro e segundo semestre de 2017 , foi a construção de "bandeiras" ou slogans por parte dos alunos, que pudessem gerar na comunidade acadêmica elementos que proporcionasse a exaltação da cultura da paz. Nestes, os discentes elaboraram frases que chamaram a atenção para o respeito à diversidade religiosa e sexual, para a inclusão social e para a conduta ética.

\section{Considerações finais}

Nas últimas décadas, o crescimento da Educação à Distância unido ao desenvolvimento contínuo das Tecnologias da Informação, suscitam, cada vez mais, a necessidade de pensar o ensino-aprendizagem e o uso de metodologias que corroborem para difusão do conhecimento.

Neste sentido, este estudo apresentou uma discussão sobre as disciplinas institucionais e sua importância para a reflexão de temas relacionados a formação humana. A inovação desta modalidade de disciplina está em oferecer para a totalidade dos discentes da instituição de ensino superior, com a finalidade de, através de atividades diversas no ambiente virtual de aprendizagem, chamar a atenção do aluno para a necessidade de refletir e repensar, de forma ética, sua conduta como profissional e cidadão. A experiência dos professores tutores demonstrou, ainda, a importância de promover a reflexão de questões do senso comum e, através dos fóruns de discussão e 
atividades propostas, construir no aluno um olhar crítico diante de temas diversos.

\section{Referências bibliográficas}

BERGMANN, Helenice M. B. Ciberespaço e Cibercultura: novos desafios para a sociedade, a escola e as formas de aprendizagem. Revista Caminhos da Geografia. Uberlândia, v. 7, n. 20, Fev/2006. p. 22-28. (Disponível em: http://www.seer.ufu.br/index.php/caminhosdegeografia/article/view/15439/8733 )

LÉVY, Pierre. O que é virtual? São Paulo: Editora 34, 1996.

MEC. Diretrizes Curriculares Nacionais para a Educação das Relações Étnico-Raciais e para o Ensino de História e Cultura Afro-Brasileira e Africana. Brasília, outubro de 2004.

SANTOS, Ednéa. Educação online para além da EAD: um fenômeno da cibercultura. In: SILVA, Marco; PESCE, Lucila e ZUIN, Antonio. (orgs.) Educação online: cenário, formação e questões didático-metodológicos. Rio de Janeiro: WAK Ed., 2010. (p. 29-48).

UNIVERSIDADE DO GRANDE RIO "Prof. José de Souza Herdy". Plano de Desenvolvimento Institucional da UNIGRANRIO- 2015-2019. Duque de Caxias: UNIGRANRIO, 2014, 166p.

UNIGRANRIO. Relatório de autoavaliação institucional 2016. Rio de Janeiro, 2017.

UNIGRANRIO. Relatório de autoavaliação institucional 2017. Rio de Janeiro, 2018. 